\title{
Environmental considerations in the Single European Sky: A Delphi approach
}

\author{
Marina Efthymiou ${ }^{\mathrm{a}, *}$, Andreas Papatheodorou ${ }^{\mathrm{b}}$

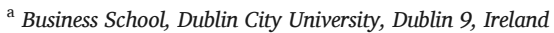 \\ ${ }^{\mathrm{b}}$ Department of Business Administration, University of Aegean, 8 Michalon Street, 82132 Chios, Greece
}

\section{A R T I C LE INFO}

\section{Keywords:}

Single European Sky

Functional Airspace Blocks

Air Navigation Service Providers

Environmental performance regulation

Delphi method

Aviation policy

\begin{abstract}
A B S T R A C T
This paper uses a Delphi approach to analyse policy issues related to the environmental aspects of the Single European Sky (SES). SES aims to organize the airspace uniformly, with air traffic control areas based on operational efficiency rather than national borders. One of the main aspects of SES is performance evaluation in four areas namely cost efficiency, capacity, safety and environment. This paper focuses on the latter using a two-round Delphi approach. The sample consists of thirty experts from airlines, Air Navigation Service Providers (ANSPs), Civil Aviation Authorities, Individual experts/consultant/academics, Governmental institutions, EUROCONTROL and the International Air Transport Association (IATA). The Delphi analysis is also supported qualitatively by five interviews with senior experts from the European Commission, EUROCONTROL and IATA. Among others, delays in implementation and the slow progress of the policy scheme are highlighted. Policy recommendations are also provided in the paper to effectively deal with the identified problems.
\end{abstract}

\section{Introduction}

The European sky is one of the busiest skies in the world with as many as 33,000 flights a day (EC, 2015). Yet, its air traffic management is organised in a fragmented way. In fact, the European airspace system covers an area of 10.8 million km² managed by 37 Air Navigation Service Providers (ANSPs) and 63 Area Control Centres (ACCs). The estimated cost of this airspace fragmentation amounts to 4 billion EUR a year (EC, 2015) and an average flight is $42 \mathrm{~km}$ longer due to fragmentation inefficiencies: this results in longer delays, higher fuel consumption, higher level of emissions and increased burden on users (EC, 2012). This fragmentation impacts adversely on flight safety, limits capacity, increases costs and slows down the decision-making process. Thus, better coordination for transferring the responsibility of an aircraft among Air Traffic Control (ATC) sectors in Europe is needed. Such an initiative to reform the architecture of the Air Traffic Management (ATM), known as Single European Sky (SES), was first launched by the European Commission in 1999.

Nonetheless, the introduction of the SES has not been a cloudless process as several challenges and difficulties have emerged in its implementation resulting in slow progress. Against this background, this paper aims to analyse the SES regulation and discuss policy effectiveness predominantly over environmental issues - these are of global dimension and significance due to climate change. Using a Delphi methodology as well as in-depth interviews, the paper investigates how the market structures, within which the SES is implemented, affect the efficiency of the scheme. Moreover, the research seeks to uncover implementation challenges regarding the SES reform and provide suitable recommendations for policymakers.

\footnotetext{
* Corresponding author.

Email address: marina.efthymiou@dcu.ie (M. Efthymiou)
} 
Compared to other areas of aviation management, only a very small number of scholars have researched the area of Single European Sky. Nava-Gaxiola and Barrado (2016) studied the expected benefit in saving flight distance after introducing the Free Route Airspace in the Southwest FAB using traffic simulation models. Baumgartner and Finger (2014) provided a brief overview of the SES. Button and Neiva (2013) using Data Envelopment Analysis estimated the potential economic efficiency of Functional Airspace Blocks. Pellegrini and Rodriguez (2013) made a comparison of the Single European Sky and Single European Railway Area. Van Houtte (2000) discussed the European Commission's main orientations and institutional arrangements for SES. Neiva (2015), Button and McDougall (2006) discussed the institutional and structure changes in air navigation service-providing organizations. Comendador, Valdés and Sanz, (2012) researched the liberalisation of Air Traffic Services in Spain. Bilotkach et al. (2015) performed a cost-efficiency benchmarking of European ANSPs, whereas Grebenšek and Magister (2013) discuss the suitability of benchmarking as a measure method for ANSPs performance. Tomova (2016) discussed the commercial revenues of ANSPs. Blondiau et al. (2016) developed economic models to analyse the performance of ANSPs. Kovacova and Balin (2017) researched the safety and capacity area of SES. There is not much research on how stakeholders assess the Single European Sky in the environmental area using Delphi method. This may prove an important contribution of this paper to the body of knowledge on the political economy of ATC reform.

The remainder of this paper is organised as follows. Section 2 examines the Single European Sky in more detail focusing among others on the role of Functional Airspace Blocks; the SES performance and charging regulations in general; and the Environment Key Performance Area (KPA) in particular. The Delphi methodology is outlined in Section 3, while Section 4 discusses the findings of the empirical research. Recommendations to policymakers are drawn in Section 5, while Section 6summarises and concludes.

\section{The Single European Sky and the role of Functional Airspace Blocks}

An airspace not limited by national borders allows the complete unification of European airspace and establishment of more direct flight paths (Kantareva et al., 2016). EC (2012) anticipates that with the implementation of the SES, safety will improve ten times, the capacity of airspace will triple, the cost of air traffic management will fall by $50 \%$ and the adverse impact on the environment will fall by $10 \%$. The first package of the legislative framework introduced in 2004 establishes the EC as the regulator for the civil sector and the Single Sky Committee to assist it in its regulatory activities, the provision of ANS, the organisation and use of airspace and the interoperability of the European Air Traffic Management Network (EATMN). The SES II Package approved in 2009 introduced the Performance Scheme, a refocus of the Functional Airspace Blocks (FABs) and a Network Manager (NM) to co-ordinate certain actions at network level.

A Functional Airspace Block (FAB) is an airspace block based on operational requirements, reflecting the need for integrated management of the airspace regardless of the existing boundaries of Flight Information Regions (FIR's), where the provision of ANS and related functions are oriented to performance and are optimized looking forward to implementing cooperative relationships between the ANSPs in each FAB (EUROCONTROL, 2008). Because FIRs are often limited by national boundaries, FABs also provide the potential to overcome bilateral restrictions, to provide a more efficient overflight from one territory to the adjacent one, and to reduce the inefficiencies in terms of safety, capacity, and cost. Table 1 reports the nine FABs established so far.

FABs extend beyond the borders of the EU. Groups were formed taking into consideration different criteria. Judging from NEFAB and Denmark-Sweden FAB geographical configuration one may conclude that these FABs' shape does not necessarily serve location requirements, but primarily traditional ties among countries. In addition, in terms of geographical coverage the FABs are not equal in size. For instance, Baltic FAB or Danube cover an area of 0.4 million $\mathrm{km}^{2}$ whereas South West FAB covers an area of 2.9 million $\mathrm{km}^{2}$. Another important element is traffic and airspace complexity. The SES total en-route service units in July 2017 were around 12.97 million (EUROCONTROL, 2018). The total en-route service units in July 2017 for FABEC were 4.33 million and for NEFAB only 467 thousands. Special Use Airspace (SUA) areas (e.g. for military purposes), increase navigation complexity and the workload of the pilots and ATCOs. Thus, the groups are not equally balanced in terms of traffic, covered area, number of States, ANSPs and traffic complexity. In any case, all the above structurally intertwine with the involved stakeholders as discussed in the next section of the paper.

\subsection{The SES performance and charging regulation}

Regulation 390/2013 (known as the Performance Regulation) identifies four Key Performance Areas (KPAs) in SES, namely (a) Safety, (b) Capacity, (c) Cost-Efficiency and (d) Environment. The Performance Scheme is developed for different periods, which are called Reference Periods (RP). The first RP covered the years 2012-2014. The second RP started in 2015 and will be completed by 2019, while the third (i.e. RP3) will start in 2020 and alternative options are currently explored (Steer Davies Gleave, 2018). An essential point in Performance Regulation (PR) is monitoring, including data collection and dissemination. If there is evidence that the targets will not be reached, then the introduction of corrective measures becomes necessary. Regulation 390/2013 considers Key Performance Indicators (KPIs) necessary to monitor, benchmark and review performance schemes for ANS and network functions.

The charging system for ANS discussed in Regulation 391/2013 (known as the Charging Regulation) is the main catalytic power for the market reforms. The European Commission admits that it would be more beneficial for the European network to have large zones according to the business needs, but with slightly differentiated rules than to continue with the same tradition of charging zones following national borders. According to the EC (2015), the five largest ANSPs, i.e. DFS in Germany, DSNA in France, ENAIRE in Spain, ENAV in Italy and NATS in the UK bear $60 \%$ of total European gate-to-gate service provision costs and control $54 \%$ of Eu- 
Table 1

Functional airspace blocks

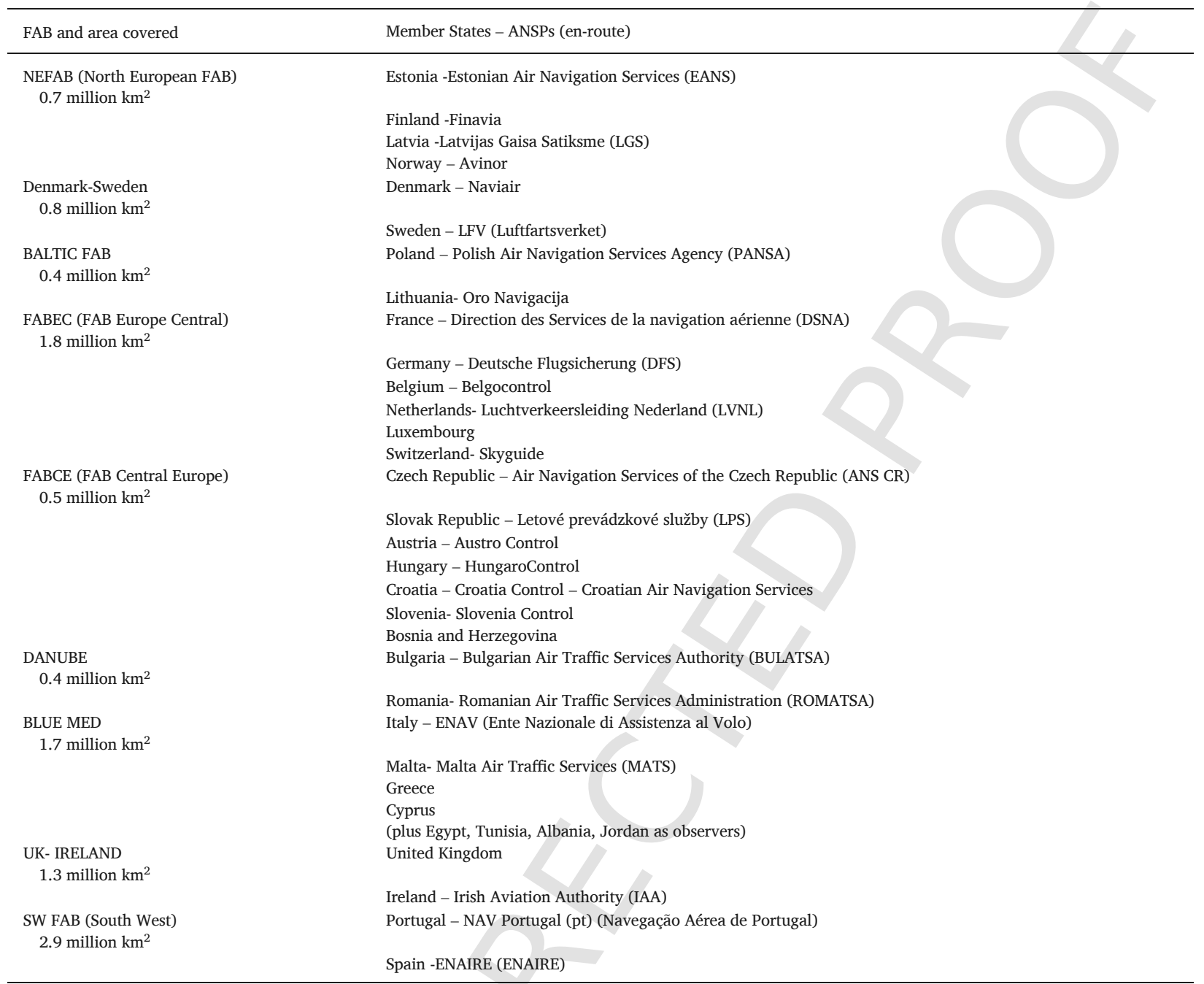

ropean traffic. Only $40 \%$ of remaining gate-to-gate costs are borne by the other 32 smaller ANSPs that control the remaining $46 \%$ of European traffic. Huet (2011) stated that it would be a utopia to say that FABs could establish one charging zone with strict common rules other than possibly in the very long-term. The charging regulation side of the performance system introduces economic incentives with a cost risk sharing system. The adjustment mechanism of risk sharing in place balances the losses and gains on a year $\mathrm{n}+2$ scale.

ANSPs are generally regarded as natural monopolists, i.e. a single supplier would have lower costs than many suppliers would. The European Commission implemented SES to regulate ANS and improve the efficiency of ANSPs towards more sustainable growth. In addition to reducing institutional market entry barriers, encouraging competition and permitting joint ventures can improve industry performance. In the former case, market participants may be incentivised to reduce unit rates and/or improve service quality; whereas in the latter, cost-related synergies and savings may also lead to lower unit rates if this is set as a prerequisite for their approval by the regulatory authorities. Such issues are studied in further detail by the Single European Sky ATM Research (SESAR)-funded Horizon 2020 COMPAIR project (Torres, 2017). The role of market forces may also increase by restructuring the nationalized industry, to create several successor companies that may be publicly owned.

\subsection{KPA environment}

ICAO (2008) identifies several environmental KPIs, i.e. the (a) the amount of emissions $\left(\mathrm{CO}_{2}, \mathrm{NO}_{\mathrm{x}}, \mathrm{H}_{2} \mathrm{O}\right.$ and particulate) which are attributable to inefficiencies in ATM service provision; (b) the number of people exposed to significant noise as measured by a three-year moving average; and (c) the fuel efficiency per revenue plane-mile as measured by a three-year moving average. From an ATM perspective, however, environmental protection is primarily and inextricably linked to flight efficiency. This can be measured horizontally or vertically. Factors influencing horizontal flight efficiency are illustrated in Fig. 1. This also shows the planning process of an optimized Flight Plan Routing. States that do not have a central archive of surveillance data use indicator option A 

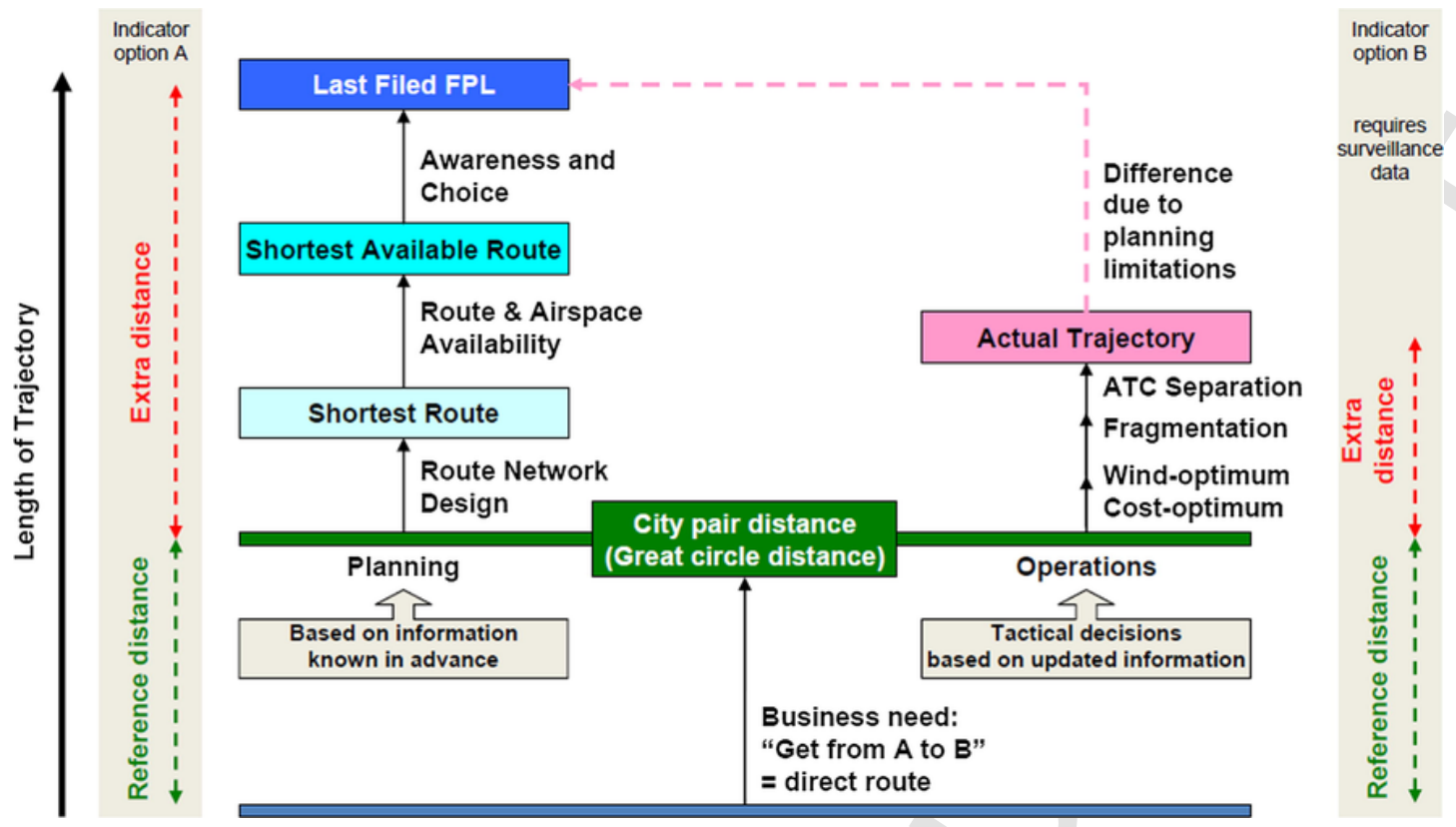

Fig. 1. The planning process of an optimized Flight Plan Routing (Source: ICAO Doc 030, 2013).

based on the last filed flight plan trajectory. If surveillance data are available (radar data, ADS-B data or other), States use the actual trajectory (indicator option B).

Furthermore, the desired outcome is not to achieve zero extra distance, since that would create operational and economic problems (ICAO, 2013). The user-preferred trajectory rarely corresponds to the direct route. Computing the indicator for wind-optimum trajectories (assuming such data are available), for example, can produce an extra distance compared to the direct route. This is because more favourable wind situations (e.g. high wind speed bands over the Northern Atlantic Ocean) can increase the groundspeed of an airplane and so reduce flight time-based costs (e.g. aircraft or fuel).

Within the Environment KPA, Regulation 390/2013 identifies horizontal en-route flight efficiency as the most important KPI. En-route congestion leads to longer trajectories to avoid en-route delays but since the introduction of RP1 in 2012 , the horizontal en-route flight efficiency continuously improves. In 2012, the actual horizontal en-route extension was 5.15\% of the Great Distance Circle (GDC), quite close to the desired target (5.12\%). An "inefficiency" of 5\% means for instance that the extra distance over 1000 NM was 50 NM. The restrictions imposed on the utilisation of the European ATS route network contribute with approximately $0.4 \%$ to the airspace utilisation inefficiency. In 2017, actual performance in horizontal flight efficiency vis-à-vis Great Circle Distance (GCD) exceeded the targeted one by 0.03 percentage points (Table 2 ).

The Environment KPA has trade-offs with other areas e.g. with the level of charges imposed on an aircraft for flying over a route. For instance, a flight Milano - Brindisi can follow different routes (PRB, 2013). In Fig. 2, two different routes are given. The green flight path is solely over Italy, whereas the red path also overflies Croatia. The GDC is shown by the dotted lines on the map. For the red flight path, i.e. the one overflying Croatia, the GDC is calculated first from Milano to the charging zone border of the Italian FIR; then within Croatia for the other intersections of the flight plan with the charging zone border between Croatia and Italy; and then

Table 2

Horizontal flight efficiency of actual trajectory (KEA) (PRU, 2018).

\begin{tabular}{|c|c|c|c|}
\hline Entity (based on FIR) & KEA (target 2017) & KEA (Actual 2017) & Difference \\
\hline \multicolumn{4}{|l|}{ Period: JAN-DEC 2017} \\
\hline SES Area (RP2) & $2.78 \%$ & $2.81 \%$ & $0.03 \%{ }^{\mathrm{a}}$ \\
\hline Baltic FAB & $1.44 \%$ & $1.63 \%$ & $0.19 \%$ \\
\hline BLUE MED FAB & $2.62 \%$ & $2.82 \%$ & $0.20 \%$ \\
\hline DANUBE FAB & $1.46 \%$ & $1.62 \%$ & $0.16 \%$ \\
\hline DK-SE FAB & $1.20 \%$ & $1.18 \%$ & $-0.02 \%$ \\
\hline FAB CE (SES RP2) & $1.90 \%$ & $1.91 \%$ & $0.01 \%$ \\
\hline FABEC & $3.14 \%$ & $3.23 \%$ & $0.09 \%$ \\
\hline NEFAB & $1.29 \%$ & $1.58 \%$ & $0.29 \%$ \\
\hline SW FAB & $3.57 \%$ & $3.25 \%$ & $-0.32 \%$ \\
\hline UK-Ireland FAB & $3.18 \%$ & $3.70 \%$ & $0.52 \%$ \\
\hline
\end{tabular}

a Days involving ATC industrial action are exempted from the analysis. 


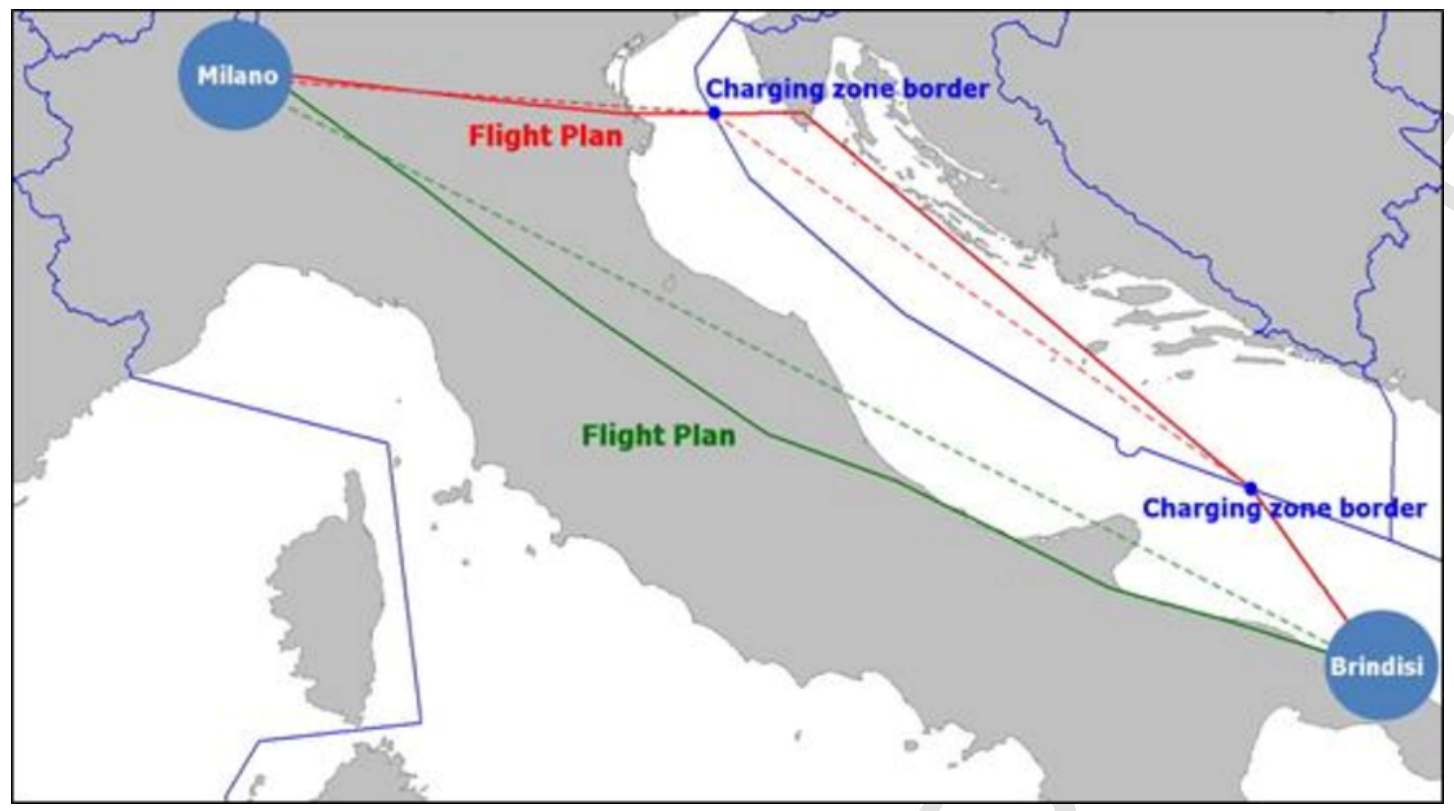

Fig. 2. Two alternative routes between Milan and Brindisi (PRB, 2013: 314).

to Brindisi. Compared to the flight plan contained entirely within Italy, the route overflying Croatia implies a reduction of $430 \mathrm{~km}$ in Italy and an increase of $477 \mathrm{~km}$ in Croatia. For an aircraft weighing 80 metric tonnes, the unit rate (per kilometre) in July 2013 was $€ 1.00$ in Italy and $€ 0.53$ in Croatia, i.e. about half the Italian rate. The longer route (over Croatia) is therefore $€ 177.19$ cheaper $(430 \mathrm{~km} \times € 1.00-477 \mathrm{~km} \times € 0.53)$. The airplane may burn additional fuel on a longer distance but this extra cost may be compensated by the savings generated when overflying Croatia. In this example, the additional distance is $47 \mathrm{~km}$ for the plan through Croatia. It is cheaper for the airspace user to file (and fly) the longer flight plan as long as its operating costs per kilometre are less than $€ 3.77$ ( $€ 177.19 / 47 \mathrm{~km}$ ). According to the 2012 PRB Annual Monitoring Report (2013: 21) 'such a situation exposes the risk of possible unintended consequences of the current rules. They might constitute an incentive for airspace users to file longer routes with a detrimental effect on the horizontal flight efficiency indicator (KEP). They might create cost competition based on Unit Rates, in order to attract traffic'.

Avoiding expensive unit rates and asking for direct routing may have negative impacts on safety due to sector overloads and on capacity due to ACC under- and over-utilisation. This may justify the introduction of a single unit rate per FAB, an action that could prove quite complex given the diverse local financial arrangements.

According to EUROCONTROL (2016), ATC can improve flight efficiency by (a) enhancing en-route airspace design; (b) maximising airspace utilization and route network availability; (c) increasing the efficiency of TMA design and utilization; (d) optimizing airport operations; and (e) raising awareness of performance. These action points could save airlines 470,000 tons of fuel per year, i.e. the equivalent of 390 million euros and 1.5 million tons of $\mathrm{CO}_{2}$ emissions (EUROCONTROL, 2016). Airframe design, weight, weather conditions and airspace, influence the optimum cruise conditions. Flight Management Systems on board of aircraft can determine the most efficient cruise altitude and speed to optimise fuel burn. ATM can assist in this process by enhancing capacity in the en-route phase of flight to offer aircraft the cruise levels and speed they request to burn less fuel. Furthermore, taking advantage of tailwind can offer efficiency gains.

Special Use Airspace (SUA) is inactive most of the time and especially during weekends. SUA leads to circumnavigation and ANSPs try to offer tactical directs (i.e. shortcuts) to accommodate increases in traffic demand. When those routings are planable, the route length is shortened, contingency fuel is reduced, and predictability is enhanced. The main reason that this part of airspace is not available to aircraft operators is that it is reserved for military use. According to ICAO (2011), airspace use should be managed in a way that accommodates the conflicting requirements of civil and military users and minimizes any constraints on operations. The Flexible Use of Airspace (FUA) concept is developed based on the above principle of flexible and adaptable airspace structures and procedures. The civil-military collaboration can be the biggest challenge to implement FUA and improve flight efficiency. Civil/military interoperability improves safety, benefits capacity and shortens routes.

All the above issues are now further highlighted in the empirical part of the paper. Section 3 discusses the research method, while Section 4 reports the results of the Delphi analysis and the in-depth interviews.

\section{Research methodology}

A two-round Delphi method was used to evaluate the Single European Sky and to identify the underlying issues affecting its success. Delphi sets the communication process allowing a group of individuals to effectively deal with complex issues (Linstone \& 
Turoff, 2002). According to Linstone \& Turoff (2002) Delphi was originally used for forecasting purposes; the method, however, has also been used to collect current and historical data not accurately known or available; to explore urban and regional planning options; to put together the structure of a model; to delineate the pros and cons associated with potential policy options; to develop casual relationships in complex economic or social phenomena and to distinguish and clarify real and perceived human motivations. Delphi may be conducted in multiple rounds. In the first round, a panel of experts, either as a group in the same room or individually in different areas, are asked about their opinion regarding a specific topic. The opinions of all the participants are summarised and sent back to the participants to reflect, develop new ideas and/or to revise their already stated ideas. Further rounds may also be introduced especially if a certain level of opinion agreement or consensus is actively sought by the researcher.

The literature (e.g. Linstone et al., 1975; Okoli and Pawlowski, 2004; Balasubramanian and Agarwal, 2013; Schmiedel et al., 2013) suggests 10-18 experts in a Delphi panel, but due to the complexity of the topic of this research as well as the number of stakeholders involved, the sample consisted of 30 experts. The identity of the participants was kept anonymous, so the potential risk of self-censorship is reduced. The questions/statements for the present research were selected after a systematic literature review of the related reports, papers and books.

The key stakeholders of Single European Sky are the regulated entities, i.e. the Air Navigation Service Providers (ANSPs), the European Commission (EC) and especially the Directorate General for Mobility and Transport (DG MOVE), the European Organisation for the Safety of Air Navigation, commonly known as EUROCONTROL that is also the Network Manager (NM) for SES.

The Civil Aviation Authorities (CAAs) refer to national regulatory bodies responsible for regulatory oversight. The National Supervisory Authorities (NSAs), established by request of the EC (Reg. No 550/2004), ensure the supervision of the regulatory framework. In some states, the NSA is incorporated within the CAA, whereas in some others it is a separate agency. The NSAs should be independent from the ANSPs to effectively oversee operations. Only in 4 out of 28 cases, a functional separation has been achieved, meaning that both NSA and the ANSP are part of the same organisation, but are internally separated to ensure independence of the NSA (SkyBrary, 2014). For NSAs to effectively convene and discuss issues pertinent to the SES, the NSA Coordination Platform (NCP) was established at a European level in 2009. The Performance Review Body (PRB) members are appointed by the EC and advise the EC on target setting and performance.

A pilot survey was conducted to a panel of experts (consisting of CAAs, EUROCONTROL, EC and ANSPs representatives) to ensure the conceptual validity of the questions. The questionnaire was then revised according to the feedback and afterwards was distributed to more than 260 qualified experts via pre-existing stakeholder email lists provided by EUROCONTROL and participants identified by the authors. The participation rate was around 15\%. The sample consisted of government bodies (i.e. EC, PRB), CAAs/NSAs, individual experts, ANSPs, EUROCONTROL, airlines, IATA.

The questionnaire is based on the existing literature related to sustainable aviation in conjunction with the specifications of the SES regulations. It aims to identify the underlying issues related to the slow implementation of SES and the ways of improving the environmental performance of commercial aviation. For instance, Civil-Military cooperation is a major issue in airspace harmonisation with important implications for the Free Route Airspace and therefore is included in the questionnaire.

The questionnaire is structured around 7 main areas. Participants were asked to express their opinion using a point in a Likert scale. The first completed questionnaire of the first round was returned to the authors on the 20th June 2014 and the last questionnaire of the second round on the 10th April 2016. The survey stopped in the second round because there were no major changes of the experts' opinions. Delphi method proved very time-consuming, but valuable and appropriate for the nature of the research. Most of the participants engaged in a wider discussion about SES and ATC, which played an important role in the recommendations made below.

The consensus and reliability of the Delphi study findings were tested using the Coefficient of Variation (CV), which is the best parametric statistical method that can be used to test reliability in a Delphi study according to Shah and Kalaian (2009). The Coefficient of Variation (CV) takes values between 0 and $\sqrt{N-1}$, where $\mathrm{N}$ refers to the sample size. In this specific case, the CV's values range from 0 to 5.39 . When the $\mathrm{CV}$ is closer to 0 it is considered low and when it is closer to 5.39 it is considered high. To measure changes in the participants' opinion the absolute difference of CV $(\Delta \mathrm{CV})$ was used; it was calculated by deducting the CV of round one from the CV of round two. Moreover, five interviews with senior experts from the EC (N.01; N.02), EUROCONTROL (N.03; N.04) and IATA (N.05) were conducted to better support the conclusions deduced from the Delphi method.

\section{Discussion of Delphi results and interviews' findings}

The Delphi questionnaire sought stakeholders' responses on the implementation issues of SES and focused on the area of environment. The questions (sets of statements) were formulated following the initial interviews and experts' consultation. On average, 26 participants replied to the question about the areas that benefit from the establishment of FABs (Table 3). The participants kept a neutral to positive position (i.e. three on a Likert scale ranging between one as minimum and five as maximum) regarding the FAB improvement areas that have been identified as the most promising according to the degree of the potential benefit deriving from the establishment of FABs. The respondents identified the Common Operational Procedures, Synergies in ATFCM, Harmonised ATM system and Reduction of Emissions as important FAB Improvement Areas (FIAs). The Common Flight Inspection has been identified as an unimportant FIA. The first question about the areas benefitted by FABs had a very low $\Delta \mathrm{CV}$ ranging from 0 to 0.07 . Hence, stability of opinions was apparent.

On average, 27 participants replied to the question about SES and the environment in the second round (Table 4). Most of them agreed that the reorganisation of the European Sky was necessary and that the airspace management had to change. They also 
Table 3

Areas that benefitted from the establishment of FABs (2nd round SES Questionnaire).

\begin{tabular}{|c|c|c|c|c|c|c|}
\hline & $\mathrm{N}$ & Min & Max & Mean & SD & $\Delta \mathrm{CV}$ \\
\hline Harmonised ATM System & 26 & 1 & 5 & 4.12 & 0.95 & 0.07 \\
\hline Common Operational Procedures & 26 & 2 & 5 & 4.04 & 0.77 & 0.01 \\
\hline Reduction of Emissions & 25 & 2 & 5 & 4.04 & 0.89 & 0.02 \\
\hline Airspace Consolidation & 26 & 1 & 5 & 3.88 & 0.95 & 0.04 \\
\hline Common Routes Network design & 26 & 1 & 5 & 3.81 & 0.90 & 0.03 \\
\hline Communication Data Sharing & 26 & 2 & 5 & 3.81 & 0.75 & 0.01 \\
\hline Common Sector Design & 26 & 1 & 5 & 3.77 & 0.95 & 0.03 \\
\hline Common Safety Management System & 26 & 2 & 5 & 3.69 & 0.88 & 0.02 \\
\hline Improved Cooperation with Militaries & 26 & 1 & 5 & 3.65 & 1.09 & 0.01 \\
\hline Surveillance Data Sharing & 26 & 1 & 5 & 3.54 & 0.99 & 0.03 \\
\hline Common ATCO Training & 26 & 2 & 5 & 3.42 & 0.81 & 0.00 \\
\hline Common Research \& Development & 25 & 2 & 5 & 3.20 & 0.87 & 0.04 \\
\hline Common Aeronautical Information Service (AIS) \& METeorological Service (MET) & 26 & 1 & 5 & 3.15 & 1.19 & 0.04 \\
\hline Common Procurement & 26 & 1 & 5 & 3.08 & 1.02 & 0.04 \\
\hline Sharing of Navigation Aids & 26 & 1 & 4 & 3.00 & 0.85 & 0.05 \\
\hline Common Flight Inspection & 25 & 1 & 5 & 2.80 & 0.76 & 0.01 \\
\hline
\end{tabular}

Table 4

Position of participants on SES and the environment (2nd round SES Q).

\begin{tabular}{|c|c|c|c|c|c|c|}
\hline & $\mathrm{N}$ & Min & Max & Mean & $\mathrm{SD}$ & $\Delta \mathrm{CV}$ \\
\hline The reorganisation of the European Sky was necessary & 28 & 1 & 5 & 4.21 & 0.96 & 0.05 \\
\hline $\begin{array}{l}\text { The European airspace network today can benefit from a significant level of dynamism through the } \\
\text { application of the Flexible Use of Airspace (FUA) concept }\end{array}$ & 27 & 1 & 5 & 3.78 & 0.97 & 0.01 \\
\hline $\begin{array}{l}\text { Due to inherent safety requirements (minimum separation between aircraft), the level of "inefficiencies" } \\
\text { cannot be reduced to zero at system level }\end{array}$ & 28 & 1 & 5 & 3.75 & 1.00 & 0.03 \\
\hline FABs bring routes closer to the Great Distance Cycle (GDC) route and reduce extended flight paths & 27 & 1 & 5 & 3.52 & 0.98 & 0.04 \\
\hline $\begin{array}{l}\text { Due to capacity requirements (organisation of traffic flows), the level of "inefficiencies" cannot be reduced to } \\
\text { zero at system level }\end{array}$ & 28 & 1 & 5 & 3.46 & 1.17 & 0.02 \\
\hline The main environmental KPI should be the estimated economic value of $\mathrm{CO}_{2}$ emissions due to route extension & 27 & 1 & 5 & 2.96 & 1.22 & 0.06 \\
\hline $\begin{array}{l}\text { The horizontal component is of higher economic and environmental importance than the vertical component } \\
\text { of the Flight efficiency }\end{array}$ & 28 & 1 & 4 & 2.54 & 0.88 & 0.02 \\
\hline All FABs are fully operational & 26 & 1 & 5 & 1.92 & 0.89 & 0.08 \\
\hline The airspace before SES was not in need of change & 28 & 1 & 5 & 1.79 & 0.92 & 0.11 \\
\hline
\end{tabular}

agreed that the FABs are not fully operational. There are extremely small differences compared to the first round. The $\Delta \mathrm{CV}$ ranged from 0.01 to 0.11 . The maximum $\Delta \mathrm{CV}$ was for the statement 'The airspace before SES did not need to be changed'. More experts disagreed with this statement in the second round.

On the third set of statements (Table 5), experts were asked to allocate a total of 100 points to different factors affecting horizontal en route flight efficiency. The 24 experts that answered, suggested that the most important factors are the airspace structure, the availability of airspace, the flight planning capabilities, tactical ATC routings and then the user preferences. The question about the factors affecting horizontal en route flight efficiency was the case where the experts revised their opinion the most compared to the rest of the questions. Nevertheless, the $\Delta \mathrm{CV}$ is quite low, i.e. 0.11 on average. Stability of opinions was hence achieved in this question.

The Civil - Military cooperation is a very important element for the reorganisation of the airspace. Therefore, the participants were asked to prioritise the factors that affect the use of the civil/military airspace structures (Free Route Airspace-FRA, Flexible use of Airspace-FUA) as seen in Table 6. The factor 'political issues' accounted for $43 \%$ on average while the remaining factors between 9 and $13 \%$. The $\Delta \mathrm{CV}$ of the Civil - Military cooperation was very low, indicating that stability of opinion was achieved. The $\Delta \mathrm{CV}$ values ranged from 0.03 to 0.25 and the average $\Delta C V$ was 0.09 .

Table 5

Factors affecting horizontal en route flight efficiency (2nd round SES Questionnaire).

\begin{tabular}{|c|c|c|c|c|c|c|}
\hline & $\mathrm{N}$ & Min & Max & Mean & SD & $\Delta \mathrm{CV}$ \\
\hline Route structure and availability affect horizontal en route flight efficiency & 24 & 5 & 50 & 27.92 & 10.52 & 0.06 \\
\hline Availability of airspace (utilisation of civil military structures) affects horizontal en route flight efficiency & 24 & 5 & 40 & 17.83 & 8.51 & 0.08 \\
\hline $\begin{array}{l}\text { Flight planning capabilities (use of software, repetitive flight planning) affect horizontal en route flight } \\
\text { efficiency }\end{array}$ & 24 & 5 & 25 & 14.67 & 5.83 & 0.11 \\
\hline Tactical ATC routings affect horizontal en route flight efficiency & 24 & 5 & 20 & 10.63 & 4.25 & 0.12 \\
\hline User preferences regarding fuel affect horizontal en route flight efficiency & 24 & 0 & 40 & 10.38 & 8.97 & 0.13 \\
\hline User preferences regarding time affect horizontal en route flight efficiency & 24 & 0 & 25 & 8.58 & 5.59 & 0.13 \\
\hline Special events such as ATC strikes affect horizontal en route flight efficiency & 24 & 0 & 20 & 7.96 & 5.07 & 0.15 \\
\hline
\end{tabular}


Table 6

Factors affecting the Civil Military cooperation (2nd round SES Questionnaire).

\begin{tabular}{|c|c|c|c|c|c|c|}
\hline & $\mathrm{N}$ & Min & Max & Mean & SD & $\Delta \mathrm{CV}$ \\
\hline Political issues & 26 & 0 & 100 & 43.12 & 27.13 & 0.04 \\
\hline Flight planning capabilities (use of software, repetitive flight planning) & 26 & 0 & 35 & 13.04 & 9.49 & 0.25 \\
\hline Special events & 26 & 0 & 50 & 12.85 & 15.37 & 0.03 \\
\hline Existing ICAO ATM procedures & 26 & 0 & 30 & 9.12 & 7.92 & 0.11 \\
\hline Aspects related to position information and radar vectoring & 26 & 0 & 30 & 9.12 & 7.66 & 0.03 \\
\hline
\end{tabular}

On average, 27 participants evaluated the factors according to their contribution to emissions' reduction and only 3 added a factor (Table 7). The factors that are considered the most important by the participants are the shortest feasible routes, the Flexible Use of Airspace (FUA), Continuous Descent Operations (CDOs) the Free Route Airspace (FRA), and use of eco-friendly engines. The factors Trading Certified Emissions Reductions (CERs) (mean $=2.78$ ), Trading Verified or Voluntary Emissions Reductions (VERs) (mean $=2.54)$ and EU Emissions Trading Scheme (mean $=2.93$ ) were evaluated as unimportant. As listed in Table 7 , the $\Delta C V$ of the opinions about factors contributing to emissions reduction is very low, proving stability among the Delphi method rounds. The minimum value of $\Delta \mathrm{CV}$ was 0 and the maximum value was 0.08 .

The 24 participants that replied to the question about the factors leading to carbon neutral growth in the second round of the Delphi method gave points ranging from 0 to 50 (Table 8). The en-route flight efficiency factors (i.e. $12.58 \%, 12.17 \%, 11.54 \%$, and $10.92 \%$ ) jointly gathered $47.21 \%$ and the EU Emissions Trading Scheme 17.5\%, airlines' carbon offsetting schemes $15.67 \%$ and states' carbon offsetting schemes gathered $10.08 \%$. Four participants added the use of biofuels and the ICAO proposed carbon offsetting scheme to the factors of importance. The difference in replies from the first round of the Delphi method is minor. The $\Delta \mathrm{CV}$ values range from 0 to 0.13 . The average $\Delta \mathrm{CV}$ is 0.042 . Consensus and stability was achieved in this question too.

As discussed in Section 2, the environmental KPA focuses on en-route flight efficiency comparing it to the GCD. The "optimal" trajectory though should consider more factors such as weather conditions (including wind optimal routes) and vertical (and speed) trajectory efficiency. Delgado (2015), also highlighted that aircraft operators may choose longer routes with lower route charges or may prioritise shorter trip times at the expense of higher fuel consumption.

Finally, the Delphi participants were asked to comment on the charging mechanism of SES. The following is a selection of replies given:

A common charging scheme based on the ideal route and not on the actual trajectory can be the solution' (IATA; CAA; EUROCONTROL; CAA)'.

Table 7

Factors contributing to emissions' reduction (2nd round SES Questionnaire).

\begin{tabular}{|c|c|c|c|c|c|c|}
\hline & $\mathrm{N}$ & Min & Max & Mean & SD & $\Delta \mathrm{CV}$ \\
\hline Shortest feasible routes & 27 & 3 & 5 & 4.30 & 0.67 & 0.05 \\
\hline Flexible Use of Airspace (FUA) & 28 & 2 & 5 & 4.18 & 0.72 & 0.03 \\
\hline Implementing continuous descent operations (CDOs) & 28 & 3 & 5 & 4.14 & 0.71 & 0.00 \\
\hline Use of Eco-friendly engines & 28 & 1 & 5 & 4.14 & 0.89 & 0.01 \\
\hline Free Route Airspace (FRA) & 27 & 2 & 5 & 4.11 & 0.70 & 0.03 \\
\hline Single European Sky (SES) & 28 & 1 & 5 & 3.82 & 0.94 & 0.05 \\
\hline Improving load factors & 28 & 2 & 5 & 3.68 & 0.77 & 0.01 \\
\hline Use of Biofuels & 28 & 1 & 5 & 3.57 & 1.14 & 0.01 \\
\hline Reduced traffic because of economic crisis & 28 & 1 & 5 & 3.43 & 1.00 & 0.05 \\
\hline Airlines develop offsetting programs & 27 & 1 & 5 & 3.26 & 1.02 & 0.05 \\
\hline EU Emissions Trading Scheme (EU ETS) & 28 & 1 & 5 & 2.93 & 0.98 & 0.08 \\
\hline Trading Certified Emissions Reductions (CERs) & 27 & 1 & 5 & 2.78 & 1.01 & 0.04 \\
\hline Trading Verified or Voluntary Emissions Reductions (VERs) & 26 & 1 & 4 & 2.54 & 0.99 & 0.04 \\
\hline
\end{tabular}

Table 8

Allocation of points by participants concerning the most important factors leading to carbon neutral growth (2nd round SES Questionnaire).

\begin{tabular}{|c|c|c|c|c|c|c|}
\hline ( & $\mathrm{N}$ & Min & Max & Mean & $\mathrm{SD}$ & $\Delta \mathrm{CV}$ \\
\hline The EU ETS leads to carbon neutral growth & 24 & 0 & 40 & 17.50 & 11.59 & 0.04 \\
\hline Individual carbon offsetting programs from airlines lead to carbon neutral growth & 24 & 0 & 40 & 15.67 & 10.48 & 0.00 \\
\hline FRA leads to carbon neutral growth & 24 & 0 & 50 & 12.58 & 9.94 & 0.01 \\
\hline Wind optimal routes lead to carbon neutral growth & 24 & 0 & 40 & 12.17 & 8.13 & 0.04 \\
\hline FUA leads to carbon neutral growth & 24 & 0 & 20 & 11.54 & 4.90 & 0.13 \\
\hline Direct routes lead to carbon neutral growth & 24 & 0 & 30 & 10.92 & 6.80 & 0.03 \\
\hline Individual carbon offsetting programmes from states lead to carbon neutral growth & 24 & 0 & 25 & 10.08 & 7.47 & 0.02 \\
\hline Other (ICAO) & 4 & 0 & 30 & 15 & 10.80 & 0.02 \\
\hline Other (biofuels) & 4 & 0 & 37 & 16.75 & 14.10 & 0.01 \\
\hline
\end{tabular}


An ANSP added 'Common FAB unit-rate (or EU wide) with compensation scheme could be the answer'.

A representative of a government body stated that 'it depends on the political strength of the EU to reduce charges'.

An airline's representative said that 'There is no such a thing as a "present charging scheme" because the regulations change every year. The charging scheme which is currently on the table (cost relative to route in European airspace) will move flights to routes passing just outside of Europe, extending flight times and increasing $\mathrm{CO} 2$ emissions'.

'For some ANSPs the targets were not very ambitious as their unit rates were below target so they only raised the unit rates. For some others, the target was unrealistic. It was very ambitious to set same targets for all but I do not think it works in practice. Should we allow those FAB's that deliver to take over those FAB's that don't?' (Airline)

Another expert stated that 'Present charging scheme goal is to return the additional ANS revenues to the Users. In addition, the ultimate goal is to create single charging zone within the FABS - with one unit rate per FAB. FAB single unit rate would ensure equal distribution of flights that are based on operational requirements and not on cost efficiency requirements as the flights are organized today within the FABs (some states are more expensive than others within the FAB and thus Users would rather fly cheaper route than more direct route - while this would have negative impact on $\mathrm{CO}_{2}$ emission - but this would be more cost effective for the User, even though they would have higher $\mathrm{CO}_{2}$ emission)'.

It is evident from the above replies that the participants are not happy with the charging scheme. Several participants suggested a charging scheme based on the actual trajectory. Strauss et al. (2016) have researched this option in Horizon 2020 COCTA project. Moreover, participants consider that the current charging scheme is not set realistically, the implementation lacks political strength and there are adverse consequences for environmental performance, since airlines select routes with cheaper unit rates and the charging scheme is not done based on the Great Distance Circle (GDC) between the city pairs. Therefore, airlines fly longer routes to pay less for ANS, consuming more fuel and having higher level of emissions.

In addition to the Delphi analysis, the in-depth interviews revealed that not all states adopt the same environmental practice and they do not have the capability or interest to deliver results at the same level. There are different targets for the countries based on their historic performance, but many times new conditions are not taken under consideration. One interviewee mentioned that for example the economic and social issues Greece is currently facing are responsible for the shortfalls of the ANSP in relation to investments in the infrastructure and human resources.

Moreover, the ANSPs are given incentives by the EC to enhance their compliance and efficiency to the Performance Regulation (PR). The risk-sharing mechanism of the charging scheme, i.e. the sharing of the financial risk between ANSPs and airspace users, is seen as a meaningful economic incentive for ANSPs to be more cost-efficient taking advantage of good management, economies of scale and productivity gains. All the interviewees highlighted the importance of incentive mechanisms for the implementation and success of SES. According to interviewees N.03, N.04 and N.05 the SES targets and financial incentives should be accompanied by effective binding performance obligations for the various ANSPs.

\section{SES and the environment: Policy recommendations}

As shown by the Delphi results, SES brought many changes in the way the various countries collaborate in ATC management. Moreover, the restructuring of the airspace and the creation of FABs contributed to the ATC management improvements in several areas as previously identified in Table 3. However, the Delphi interviewees considered that despite these improvements, the SES has not delivered to the desired level environment-wise mainly due to the lack of effective economic incentives for the ANSPs. Recommendations to deal with these problems now follow.

\subsection{Environmental prioritization by ANSPs and CAAs}

The creation of FABs and the implementation of FUA and FRA, the improvements in the communication and data sharing on the decrease of the en-route delays may have positive repercussions for environmental performance. The KPA of Environment in the PR is not exactly a separate target, but one could argue that it benefits from improvements in the other areas as highlighted by the Delphi results. The targets set in the PR assist in measuring the benefits, but also in promoting the mentality of environmental protection.

Still, environmentally friendly attitudes and practices are not common across all the ANSPs and countries. As discussed in the literature review, some of the ANSPs have implemented additional measures to protect the environment. On the other hand, some ANSPs prioritise other KPAs and environmental protection is not among their priorities. To promote consistency among ANSPs and handle the global problem of climate change, a change of mentality is deemed necessary.

The most effective action to increase environmental awareness is to change the mentality of ATCOs, ANSPs employees and CAAs employees as suggested by several interviewees and Delphi participants. As discussed in Section 2 of this paper, changes in the en-route design can improve airspace utilisation and network availability. To avoid en-route delays ATCOs often offer extended routes to pilots. Airspace architects should reconsider the trade-offs of KPA environment with the other KPAs and incorporate the environmental externalities and social costs. Moreover, regulators need to reconsider the KPIs and maybe include noise- and local air quality pollution in the performance regulation.

Public environmental awareness and education can be applied either by each state or centrally by the EC or NM. Should the training be developed and delivered from the CAAs/NSAs or Ministries of Transport, the implementation is expected to be self-defeating. The reason is that the educators most probably share the same mentality and do not prioritise environmental protection and 
sustainable development. If the training were organised by a central authority like the EC or EUROCONTROL, there would also be fewer transaction costs due to economies of scale.

In addition, available conditional routes are not used to the maximum degree, due to short notice or due to airline Operational Control Centre's difficulty to change flight plans. Therefore, airlines should be informed about the implemented solutions regarding the CDRs and a better communication channel should be developed to realise such a change of routes. Implementing this recommendation is important and necessary and characterised by relatively low cost; acceptance by the stakeholders; and radical change effects to the mentality regarding environmental protection.

\subsection{Incentive mechanisms}

In terms of mitigating climate change at the en-route level from an operational perspective, the main stakeholders are the airlines and the ANSPs. Airlines have an incentive to reduce their emissions based on the principle that excess fuel consumption costs them money. ANSPs, on the other hand, have no financial incentive-other than the SES PR- to be more environmentally friendly.

Price differentiation for routes that are closer to GDC could be an option. The ANSPs can modify the charging scheme and charge by route. Routes identical or almost identical to GDC could be assigned to airlines that are willing to contribute more to the use of these routes. Bad weather conditions and other unplannable circumstances need to be taken under consideration. The principles of slot trading could support this mechanism. For the time being, this scenario looks unrealistic, but it could be an effective solution in case the nature of ANSPs changes and consolidation is achieved or in case ANSP alliances are reinforced and promoted.

The existing PR includes economic incentives when the ANSP performance is above the expected targets. Blondiau et al. (2016) suggest introducing hybrid price-caps in the SES PR, rewarding ANSPs for outperforming service quality targets through a bonus-malus scheme. In the medium term, the ANSPs could be reshaped to have a centralised en-route level handled by a single company or authority, and a terminal level that is not under monopoly provision. This would promote consistency among the different sectors, reduce the number of sectors and improve data sharing leading to improved, more direct routes. The implementation of this recommendation can be time-consuming and bears many bureaucratic procedures, but it is a very effective way to encourage an environmentally friendly practice.

\subsection{Consolidation and financing}

The economic situation and the readiness of the countries are not at the same level. The performance targets are set at national/ FAB level and at EU-wide level. Nevertheless, it is not very clear how these targets are set. They can be set at individual rate, at sectoral rate or a combination of both. The hybrid option could balance the pros and cons of the individual rate and sectoral rate options. It could be one level ahead of the existing regulation, offering flexibility and accommodating the needs of fast growers, new entrants and early movers to make the implementation of the regulation fairer for all the players. In case some ANSPs face problems to reach the agreed targets, the possibility to amend the targets should be available.

Some ANSPs have already acted before the implementation of the Performance Scheme to improve their efficiency. From a fairness perspective, these early adopters should be rewarded but they would be ignored if the targets were allocated based on the sectoral rate. Moreover, regarding capacity and environment, the efficiency of ANSPs in the European Civil Aviation Commission (ECAC) is affected by the efficiency of other ANSPs that are not based in ECAC, but that handle traffic entering the ECAC airspace. Therefore, the scope of SES and the performance scheme could be extended to capture the actions of the neighbouring ANSPs.

The current aviation system in terms of ANS provision is based on natural monopolies (Viscusi et al., 2005) or, in the best of cases, on oligopolistic competition for a temporal monopoly at a terminal level (i.e. tendering/competition for the market monopoly). The cost of infrastructure as well as the cost of service provision is very high which results in high charges for both the airlines and the passengers. Furthermore, some ANSPs cannot increase their CAPEX due to financial problems. For example, the Greek ANSPs' revenues from the charges are not necessarily reinvested to the ANSP thus contributing to infrastructure improvements, but they may be allocated to other sectors, such as healthcare or education. Consequently, there might be inefficiencies in the aviation systems affecting all the other ECAC members. If a special financing system from the EU is implemented to financially support those ANSPs for technological improvements, this may create a moral hazard for other countries to also misallocate funds.

Most of the ANSPs handle a small share of movements, but they still need the entire infrastructure. Traffic movements are concentrated in 4-5 ANSPs. Nevertheless, this does not necessarily mean that only those 4-5 ANSPs are needed to provide ANS. Services can be provided from the most efficient and effective ones (one or two) regarding safety, capacity, environment and cost efficiency factors. The system may be more efficient if the number of ANSPs were reduced or if some of the ANS were centrally provided by a separate entity. This recommendation is quite controversial and may trigger a series of reactions from the trade unions. However, due to increased competition among the ANSPs, it may become a reality in the coming future and it is better to organise and plan for this transition in a way as seamless as possible.

\section{Summary, conclusions and the way forward}

The Single European Sky is one of the most ambitious initiatives of the EU Directorate-General for Mobility and Transport aiming to improve safety and capacity of the airspace; to make air traffic management more cost efficient; and to reduce the environmental impact of aviation operations in Europe. This paper used a two-round Delphi approach and interviews with key stakeholders to in- 
vestigate policy issues related to the environmental aspects of SES. The respondents seem to acknowledge the improvements achieved by the introduction of FABs, but remain concerned about implementation delays and slow progress in general due to resistance to change and lack of economic incentivisation of ANSPs. On these grounds, the paper made recommendations related to environmental prioritization by ANSPs and CAAs; the creation of incentive mechanisms; as well as consolidation and financing of ANSP operations. As the third Reference Period is scheduled to start in 2020, some of these recommendations may prove useful to policymakers when setting the framework for the way forward. Future research may, therefore, extend the current Delphi approach to incorporate the expectations of experts regarding changes in the status quo towards a better organisation of ATC management in Europe and the world in general.

\section{References}

Balasubramanian, R., Agarwal, D., 2013. Delphi technique - a review. Int. J. Publ. Health Dent. 3 (2), $16-25$.

Baumgartner, M., Finger, M., 2014. The single European sky gridlock: a difficult 10-year reform process. Utilities Policy 31, $289-301$.

Bilotkach, V., Gitto, S., Jovanović, R., Mueller, J., Pels, E., 2015. Cost-efficiency benchmarking of European air navigation service providers. Transport. Res. A: Pol. Pract. 77, 50-60.

Blondiau, T., Delhaye, E., Proost, S., Adler, N., 2016. ACCHANGE: Building economic models to analyse the performance of air navigation service providers. J. Air Transp. Manage. 56, 19-27.

Button, K., Neiva, R., 2013. Single European Sky and the functional airspace blocks: will they improve economic efficiency?. J. Air Transp. Manage. 33 (C), 73-80.

Button, K., McDougall, G., 2006. Institutional and structure changes in air navigation service-providing organizations. J. Air Transp. Manage. 12 (5), 236-252.

Comendador, F.G., Valdés, R.M.A., Sanz, L.P., 2012. Liberalisation of air traffic services in Spain. Transp. Policy 19 (1), $47-56$.

EC, 2012. Guidance Document: The Accreditation and Verification Regulation Verification Guidance for EU ETS Aviation. Brussels, EC. Available from: < http://ec. europa.eu/clima/policies/ets/monitoring/docs/gd_iii_aviation_verification_guidance_en.pdf > (Accessed 03 February 2015).

EC, 2015. Evaluation of the Single European Sky (SES) performance and charging schemes. Available from: < http://ec.europa.eu/smart-regulation/roadmaps/docs/ 2016_move_015_evaluation_single_european_sky_performance_en.pdf $>$ (Accessed 03 June 2016).

EUROCONTROL, 2008. Evaluation of Functional Airspace Block (FAB) initiatives and their contribution to Performance improvement. EUROCONTROL, Brussels. Available from: <http://www.eurocontrol.int/sites/default/files/publication/files/prc-evaluation-of-fabs-high-quality-graphics.pdf > (Accessed 3 October 2016).

EUROCONTROL, 2016. Airspace developments and the Flight Efficiency Plan (FEP). Available from: <http://www.eurocontrol.int/articles/ airspace-developments-and-flight-efficiency-plan-fep $>$ (Accessed 3 October 2016).

EUROCONTROL, 2018. En-route service unit dashboard. Available from: < https://www.eurocontrol.int/ServiceUnits/Dashboard/Selection2018vs2017.html\#> (Accessed 7 August 2018).

Grebenšek, A., Magister, T., 2013. Is European benchmarking methodology favouring a narrow segment of air navigation service providers?. J. Air Transp. Manage. 27, 29-33.

Huet, F., 2011. The regulation of air navigation charges. In: Crespo, D.C., Mendes de Leon, P. (Eds.), Achieving the Single European Sky: Goals and Challenges. Kluwer Law International, The Netherlands.

ICAO, 2008. ICAO DOC 9883 - Manual on Global Performance of the Air Navigation System. Montreal, Canada.

ICAO, 2011. Civil/Military Cooperation in Air Traffic Management. ICAO, Montreal.

ICAO Doc 030, 2013. EUR Region Performance Framework Document. ICAO, Montreal.

ICAO Doc 9161, 2013. Manual on Air Navigation Services Economics. Available from: < http://www.icao.int/publications/Documents/9161_en.pdf> (Accessed 12 July 2016).

Kantareva, M., Angelova, A., Iliev, L., Efthymiou, M., 2016. ICAO Action Plan on Emissions Reduction, Republic of Bulgaria. General Directorate of Civil Aviation Administration Republic of Bulgaria. ICAO, Montreal.

Kovacova, M., Balint, J., 2017. Single European Sky vision: increase capacity 3 times, reduction of ATM cost by half and ensuring improvement of safety by 10 times-how to satisfy this goal in safety area?. Transp. Res. Procedia 28, 89-98.

Linstone, H.A., Turoff, M., 2002. The Delphi Method: Techniques and Applications. Addison-Wesley Publishing, S.1..

Nava-Gaxiola, C.A., Barrado, C., 2016. Performance measures of the SESAR Southwest functional airspace block. J. Air Transp. Manage. 50, $21-29$.

Neiva, R., 2015. Institutional Reform of Air Navigation Service Providers: A Historical and Economic Perspective. Edward Elgar Publishing.

Okoli, C., Pawlowski, S.D., 2004. The Delphi method as a research tool: an example, design considerations and applications. Inform. Manage. 15-29.

Pellegrini, P., Rodriguez, J., 2013. Single European sky and single European railway area: a system level analysis of air and rail transportation. Transport. Res. A: Pol. Pract. 57 (C), 64-86.

PRB, 2013. PRB Annual monitoring Report 2012, Volume 1, European overview and PRB recommendations. Brussels: EUROCONTROL. Available from: < http://www. EUROCONTROL.int/sites/default/files/content/documents/singlesky/pru/news-related/2013-19-13_prb_monitoring_report_2012_volume_1-_european_overview_ and_prb_recommendations.pdf $>$ (Accessed 10 May 2018).

Regulation EC No 390/2013 on Laying Down a Performance Scheme for Air Navigation Services and Network Functions.

Regulation EC No 391/2013 Laying Down a Common Charging Scheme for Air Navigation Services.

Regulation EC No 550/2004 on the Provision of Air Navigation Services in the Single European Sky.

Schmiedel, T., Vom Brocke, J., Recker, J., 2013. Which cultural values matter to business process management? Results from a global Delphi study. Bus. Process Manage. J. 19 (2), 292-317.

Shah, H.A., Kalaian, S.A., 2009. Which is the best parametric statistical method for analyzing Delphi data?. J. Modern Appl. Statist. Methods 8 (1), 226-232.

SkyBrary, 2014. National Supervisory Authority. Available from: < http://www.skybrary.aero/index.php/National_Supervisory_Authority > (Accessed 3 October 2016).

Steer Davies Gleave, 2018. Impact assessment of options for the regulatory approach in RP3 of the SES Performance and Charging Schemes. Steer Davies Gleave, London: . Available from: < https://ec.europa.eu/transport/sites/transport/files/studies/2018-ia-options-regulatory-approach-rp3-ses-performance-charging-schemes. pdf $>$ (Accessed 25 May 2018).

Strauss, A., Starita, S., Jovanovic, R., Ivanov, N., Fichert, F., (2016). Maximizing ATM cost-efficiency by flexible provision of airspace capacity. In: Proceedings of the Sixth SESAR Innovation Days Conference, Delft.

Tomová, A., 2016. Are commercial revenues important to today's European air navigation service providers?. J. Air Transp. Manage. 54 , 80-87.

Torres, J., 2017. An agent-based model of Competition in ATM. COMPAIR Workshop. 20th October, Brussels.

Van Houtte, B., 2000. Towards a single European sky: initiatives by the European commission to reform air traffic management. Air \& Space Europe 2 (5), $24-27$.

Viscusi, W.K., Harrington, J.E., Vernon, J.M., 2005. Economics of Regulation and Antitrust. MIT press. 